\title{
Leadership and Faith in a School Tragedy: A School Principal's Perspective
}

\author{
Ruth Tarrant*\# \\ School of Psychology, Massey University, Wellington, New Zealand \\ Email: ${ }^{*}$ R.A.Tarrant@massey.ac.nz
}

Received 21 November 2013; revised 23 December 2013; accepted 18 January 2014

Copyright (C) 2014 by author and Scientific Research Publishing Inc.

This work is licensed under the Creative Commons Attribution International License (CC BY).

http://creativecommons.org/licenses/by/4.0/

c) (i) Open Access

\section{Abstract}

On April 15, 2008, six students (aged 16 years) and one teacher (aged 29 years) from a New Zealand school lost their lives in a river canyoning tragedy. The present study investigated the school principal's perspective of how he led his school through the tragedy, and the role of faith in the school's coping. The school principal was interviewed two years after the event. The school's Christian foundation was the fundamental source of strength and guidance for the principal, as well as for students, staff, teachers, and families in the immediate aftermath of the tragedy and in the two years following (i.e., to the time of the present study), the Christian culture of the school guiding decision-making. Support from outside the school (e.g. critical incident support; teaching support from other schools; social support from community agencies and civic leaders) also played an important role in assisting the school through the tragedy, particularly in the immediate aftermath of the event. Further studies are required that allow the voices of children, families and school staff to be heard regarding leadership strategies that impact on them through a disaster.

\section{Keywords}

Tragedy, School, Leadership, Faith, Coping

\section{Background}

On April 15, 2008, six Year-12 students (aged 16 years) and one teacher (aged 29 years) from Elim Christian College (ECC) in Auckland, New Zealand, lost their lives in a river canyoning tragedy. The group was attending an outdoor education programme provided by an independent provider in a hilly, bush-clad region of the central North Island of New Zealand. The river rose rapidly after heavy rain, stranding the canyoning group on a ledge

\footnotetext{
${ }^{*}$ Corresponding author.
}

"Dr Ruth Tarrant is a Research Associate in the Joint Centre for Disaster Research (Massey University/GNS Science), and lectures in the School of Psychology at Massey University, Wellington, New Zealand. 
above the water. An attempt to leave the ledge and exit the river before the river rose further resulted in multiple loss of life. The canyoning group comprised 10 people: eight students; one teacher; and an instructor employed by the outdoor education centre. Two students and the instructor survived the activity. There was considerable media coverage of the tragedy in the days immediately after the tragedy and at various times in the years since as enquiries and inquests were completed.

The present study is part of a larger study investigating leadership of a New Zealand school responding to a tragedy. In the course of conducting the larger study, it was evident that the Christian foundation of the school was integral to guiding decisions and courses of action taken by the school from the moment news of the tragedy broke. The present study investigates the role of leadership and faith in a school's coping with tragedy.

Many studies have reported that following a traumatic event, people who have a religious faith experience lower levels of stress ... than those without a faith (e.g., Koenig, McCullough, \& Larson, 2001; Laufer, Raz-Hamama, Levine, \& Solomon, 2009). Meisenhelder (2002) proposes that decreased stress is a result of: 1) the comfort people experience as they turn to a higher being for love and a sense of meaning in particular events; 2) collaboration and a reduced sense of isolation as they feel in touch with a higher being who can increase their strength and hope; 3) control regained over their own lives as they surrender control to a higher being; and 4) a connectedness with others as they share their pain and receive comfort and support from others in a shared community of faith.

Similarly, Tix and Frazier (1998) suggest that social support from within the religious community is one of three broad pathways to religious coping in stressful situations, the other two pathways being the ability to cognitively restructure the event to give it meaning, and a sense of control that can be gained by trusting in God. Meisenhelder (2002) asserts that behaviours such as church attendance and prayer do not in themselves result in reduced stress or grief; what matters is the individual's perception of God and the interpretation of the stressful event in the context of the individual's faith. Bussell and Naus (2010) demonstrated that people with a faith in God were more likely to reframe a traumatic experience in positive terms. Tix and Frazier (1998) state that overall, studies demonstrate that religious coping provides a predictive component for adjustment to stressful events that "cannot be accounted for by other established predictors" (p. 420).

In a study of leadership following a tragedy where the CEO and 49 other personnel from Wilhelmsen Lines (WL: a Norwegian shipping firm) died in an air crash in 1989, McCarthy, Connell, and Hall (2005) discuss four challenges facing the new company leader in the aftermath of the event: honouring the personal losses of colleagues and families; honouring the culture of the organisation; identifying an effective management approach; and developing strategies for moving forward. In the early stages of WL coping with their losses, the leader of the organisation was attentive in sharing his personal values and beliefs with the employees, while encouraging people to share their own values and emotions. McCarthy et al. state that crucial roles of the leader following a corporate tragedy include: acting consistently on personal values; learning from mistakes; being alert to feedback on leadership style; being directive where required; clearly communicating information or requests for information; and, importantly, being adaptable in terms of strategies for problem solving. Similar elements of effective leadership in a tragedy are discussed in a study of schools responding to crises (Cornell \& Sheras, 1998). For instance, Cornell and Sheras state that successful school leaders require a clear understanding of how their school functions in terms of its "vision" or culture, and that leaders should have a well-developed understanding of the school's culture, as this is the basis for critical decision-making. Cornell and Sheras go on to state that it is important school leaders provide clear information to the students, staff and families to avoid ambiguity, as well as leaders assisting in building a sense of security, understanding the grieving process, and providing for personalguidance and support where required.

The present study reports on the school principal, Mr. Murray Burton's (MB), perspective of how he led his school through the tragedy, and how faith assisted him and his school in their coping with adversity.

\section{Method}

\subsection{Participant}

The principal of the school was interviewed in his school office. The duration of the interview was two hours. MB was invited to talk about how he led the school from the time of the disaster-event through to the time of the interview (almost two years after the tragedy), and how the school was assisted in their coping with the event.

At the time of the interview, MB had been principal of the school for seven years and was still in the position. 
At the time of the tragedy (April 15, 2008), the school had a roll of 540 students from Years 1 - 13. In total, MB had been a teacher for 28 years, 21 of those as a principal, and at the time of the tragedy he was aged 50 years. MB had also undertaken various leadership roles in churches over a period of 25 years.

\subsection{The Interview}

There was no structured set of pre-determined interview-questions to work through in the first instance, as the researcher did not want to impose any questions or themes but, rather, wished to hear MB's personal account of leadership from his own perspective. For two hours, MB, discussed his leadership of the school, and discussed the role of faith in coping with the tragedy. MB was open in his account of events, describing how he and his support team acted and reacted from their Christian foundation as the tragedy unfolded and through the following two years. MB discussed the many and varied issues the school faced, and the need for decisions that arose immediately and in the aftermath of the tragedy.

\subsection{Analysis and Analytical Procedure}

The recorded data were transcribed verbatim, and checked. There was no set of hypotheses or assumptions, as such assumptions may have missed out important aspects of the principal's experience. Instead, an inductive approach was appropriate for the present study as this allowed themes to be firmly linked to the data, the data themselves driving the analysis. The data were analysed using thematic analysis, this approach allowing an essentialist or realist view of the data to report the experiences of the interviewee from a practical, personal, and faith-based perspective.

The identified themes were investigated in relation to recent literature concerning religious faith and coping in adversarial or traumatic events, with findings considered in terms of their broader meanings and implications for coping with adversity.

\section{Results and Discussion}

To provide a coherent context for the material in this section, a brief chronological background of events is included where appropriate.

\subsection{Culture of the School: A Christian Tradition}

The school in the present study (ECC) is a state integrated school. In New Zealand, state integrated schools provide education according to the government's Ministry of Education guidelines, but education is delivered within the special character of the school, usually a particular religious tradition (Ministry of Education, 2010). ECC is founded on Christian beliefs and values, where Christian values are threaded through the school programme, and guide the conductance of the school at all times.

The news of the tragedy broke on television before the principal and school had had any confirmation of the event or of any deaths. Immediately following the television news at $6 \mathrm{pm}$, a number of students and parents from the school and wider community began to gather at the church chapel next to the school for prayer and social support. Prayer and fellowship continued throughout that evening until after midnight. During the evening, the Police were in phone contact with the principal, but released information to him bit by bit. Although by midnight the Police had given the school principal the names of all six students and the teacher who had lost their lives, the parents of those who had died were yet to be told by the Police (the required protocol in New Zealand). From the day following the tragedy, the chapel was opened from 7 am to 11 pm daily for several weeks for students, bereaved families, and others affected by the tragedy to visit at any time to pray, to leave messages or flowers, and to be supported by other people. During this time, rather than having forms of shrines in classrooms, the chapel represented a place of support and comfort for the students. The school allowed students to visit the chapel at any time they wished during the school day. In this way, the school allowed for individual students' needs for grieving.

In the days immediately following the tragedy, MB brought his school staff together three times a day to keep them fully informed about matters related to the tragedy, and to pray for God's guidance and blessing. MB also recognised that in this difficult situation, staff were likely to need, and would benefit from, the increased social support from colleagues who shared their faith. 
I think you have got to keep people fully informed. There was just tears and grief, but they all came gether .... Over a period of three to four months, I saw the staff grow because of the coming-together. You've got to draw people together, and it's all about building around the core values of your culture. As a Christian school we are very used to praying together - to us that was important ... so I would always pray.

Through the national and international publicity attracted by the event, offers of help to the school came in the form of, for example, prayers for the families, students, and school staff, as well as assistance with counselling, and practical assistance with the school's operations (e.g., teaching support). The school also received support in the form of thousands of written expressions of sympathy, gifts and food. MB commented on how the Christian character of the school guided his decisions in terms of accepting the many and various offers of help from outside the school. For example, messages required school approval before they were passed on to the families; some school supporters may have sent messages that, though well-meant, may not have been helpful to the families.

Even though help is given, I think it's the ability of you to handle that help. And I think that the help has to be in the context of what the school is all about [i.e., a Christian school].

A few weeks after the event, the school sent thousands of individually addressed messages of thanks to all identifiable supporters for their expressions of sympathy and for the support they offered, messages that also acknowledged the grief of the senders themselves. Thousands of messages went out thanking supporters, and the school principal signed all of the messages personally.

\subsection{Faith}

As at other times in school life, the Christian faith formed the foundation for the school's operation and decision-making in the tragedy, faith providing their fundamental source of support through the unique, prolonged, and mentally and emotionally demanding time. Prayer was an intrinsic aspect of coping.

Our faith is around a relationship with Jesus who we believe to be God's son. ... and we communicate through prayer.

The school experienced the empathy and support of others who prayed with them and for them, and in the prayer there was a sharing of grief.

I think also it is a way of helping others compassionately—to take them aside, and say, Can I pray for you? ... You understand where they come from. We ... all feel a bit better as a result of that.

Prayer is an integral part of a Christian's relationship with God, prayer providing an intimate connection with God in good times and in bad. Committed Christians believe there is power in prayer, and prayer is part of school life at ECC.

I think that prayer does change things. I think it's empathetic, and very comforting to know there is someone who would ... pray with you or over you, or read prayers together. It's a way of bringing people together with a purpose. There is a sense of connection with each other as well [for] those who are devout Christians.

When Christians come together, they can feel a special bond where they are linked by a shared faith in a God whom they believe will uphold them, whatever the circumstances. For instance, Christians are upheld by the reassurance of biblical texts such as: "The Lord has promised that he will not leave us or desert us" (Holy Bible, Hebrews 13:5). The ECC school motto, For I know the plans I have for you ... plans for good and not for evil, to give you a future and a hope (Holy Bible, Jeremiah 29:11), is founded in the Biblical scriptures. In times of distress, as well as in good times, Christians take comfort and strength from the bedrock of the scriptures. Religious faith not only guides the lives of Christians, but provides them with a sense of meaning (Meisenhelder, 2002; Tix \& Frazier, 1998).

The school principal felt personally supported by Christians around the country, and believed that God's hand had guided his decisions in the first few days of the tragedy in particular.

This might sound a bit strange, but I believed in those [first] three or four days, that the reason I was successful, if you could use that word, was because like-minded people were praying for us around the country. And everywhere I go, people say, Oh, we prayed for you ... so it was very, very tangible for us in that sense. It was very unifying. It was strengthening and assisting. In times of crisis like this, we are heavily relying on the fact that we can say, Lord, help.

MB goes on to comment on how their faith sustained them throughout the tragedy and the time since.

I'm ... pleased that when the chips are down, that's when we don't discard [that] which is important to us. ... 
[When] we were really in a hole [with] this tragedy that we actually continued to be authentic in terms of going to God for help.

The school compiled a DVD to record its own response in the early phase of the tragedy. The DVD contains footage from media coverage of the event, and also contains commentaries from senior students at ECC about how they were coping with their loss. Students frequently expressed confidence that God would uphold them in their grief, that prayer continued to be a source of comfort and support for them, and that their faith in God remained their strength. The commentaries by the students conveyed a deep conviction of the sustaining power of their faith.

\subsection{A Christian School Assembly the Morning after the Tragedy}

In respect of holding a school assembly the morning following the tragedy, a member of the New Zealand Ministry of Education's Traumatic Incident (TI) team (RP) who had come over to the school on the night of the tragedy, advised the principal against holding a school assembly the very next morning: RP feared the school would not be able to contain the expected widespread grief and emotion. MB considered RP's advice, but believed that an assembly at EEC was appropriate in this instance because assemblies were the forum for not only talking about school operational matters, but also for sharing Christian messages. It was their Christian faith that MB expected would be their strength and anchor in this testing and traumatic time.

That's why we had the assembly when RP said, don't have the assembly. That's why we didn't have shrines in classrooms where other schools have had. So, you take the help, and you shape it, because you know your school.

I did know that lots of schools were supplying their guidance counsellors, and coming straight to us. And, within our own Christian school we had pastors [and] teachers who were ... certainly empathetic to people. We use assemblies here to transmit our key messages ... and students know that they come to get the [Christian] message. So we were absolutely convinced that we wanted to have the assembly, so we said to RP, "We know the culture of our school." And this is where a leader has to say at some point ... I have to make a decision based on what I know about my own organisation.

At the assembly, students were all given the news of the tragedy together; they were told who had died and where the tragedy had occurred. The principal prayed with the students, and told students they did not need to leave the assembly hall until they felt ready to go back to their classrooms. Over the next two hours, the ECC counsellor and counsellors who had come to ECC from other schools talked with students, and EEC teachers talked and prayed with students until the last child left the assembly hall.

I led from the front and then we opened it up. We told everyone: "No need to go. We've got counsellors here who are going to circulate around, we've got pastors, and we are just going to move around and talk to people, pray with people, [and] console people. As you feel fit, you can move off back to your classroom, and your teachers will be waiting." And it was just an incredible process. It worked over a two-hour period until the last little one went.

In this critical stage of students and staff coming together for the first time after the tragedy, MB and his support team ensured that support was immediately available for all students and staff. Prayer was part of the support, and consistent with the character of the school.

\subsection{Adversity and Potential for Growth: The Students}

Where people meet a challenge successfully, this helps them prepare for other difficulties they may encounter in their lives (O'Leary, 1998). MB stated that he believed the students who had been affected by the tragedy would likely experience some positive changes in their lives:

My assumption is simply based on the fact that whether we like it or not, adversity is a necessary ingredient in the shaping of character. I think I've seen the fact that adversity can produce tremendous character.

At ECC, students were provided with a great deal of on-going support to help them cope with the significant losses they experienced, and with the psychological demands of an extraordinary situation. Ongoing support included, for example: Christian grief-counselling; flexibility during school-time for individual expressions of grief; opportunities for reflections and tributes; continuing vigilance and support for students who were having difficulty coping; and assistance for families and grieving siblings to access grief counselling. MB expected the 
support students received would assist them to grow from their exposure to such adversity.

In that tragedy, the kids saw the awfulness of human life, the loss of human life. They saw dreams shattered. They saw families torn apart. They saw things happen that they cannot understand and they cannot explain, and they wish they could change. They saw a whole raft of human experience, and I maintain that if we have guided them correctly, and the nets have been around them, and [through] the times of compassion and of counselling, that they would have built a fresh sense of resilience and determination to live life to the full-knowing that life is never all about plain sailing.

MB believed that adversity in people's lives can build character. Together with the Christian support the students received, MB believed the students affected by the tragedy would grow and develop from the difficulty of their experience and the demands made of them as teenagers.

Sometimes you just have to grit it out and come through the other end. It's a whole oyster-pearl thing.... [You need] the agitation of the sand.

While students were trying to understand the tragedy, and were seeing that "life is not all plain sailing," the school provided Christian counselling and support for and around the students. In the course of counselling and support provided for the students, students received messages regarding Christian principles of love and forgiveness:

Some people can come unstuck in their grief. ... people who say I can't forgive, or I can't move on. I think ... there is a measure of forgiveness that you must apply to a situation-to a person-for your own healing to take place.

I think that part of the holistic nature of our schools is really to say we are not churning out just academics, but we are hopefully producing people who can make a meaningful contribution ... to a civil society. We may not hear ... the results of that, and you may not be able to quantify [it], but it would be an interesting study to actually track these kids and see where they go-and whether any of that could be attributed back to the fact that they learnt some valuable lessons from [the tragedy they experienced in] 2008.

Joshi and Lewin (2004) assert that resilient children seek out positive people. Within schools, resilience can be fostered by principals promoting a supportive and respectful environment through constructive, empathetic involvement with students and staff at an individual and collective level. MB provides evidence that appears to support the value and relevance of the constructive support the school provided for the senior students at ECC following the tragedy:

I have to make a comment about the resilience of our current generation. ...-these kids were so resilient. If you look at the Year-13s last year (they were the ones that were in the tragedy the year before), ... apart from a couple of kids, they were as stable as they could be.

Their results were down somewhat in external examinations, but not dramatically. They seemed to process and work with and work through the situation incredibly well.

While assessing children's mental health was not within the parameters of the present study, it appears that the school provided an environment of strong and on-going psychosocial support for the students. In the face of adversity, students had been enabled to learn that it is possible to keep going, to cope, and to move ahead.

I pay tribute to that generation of kids.... I can't get away from the fact that [our jobs] are to manage what it is. I don't know whether it's just managing relationships, or to continually inspire people that we have to keep on getting up and going again. And we can do this. The world's history is littered with incredible people's stories-stories of people who have done that.

\subsection{Adversity and Potential for Growth: The Principal}

The principal believed he himself had grown from his involvement in the tragedy, having been extended into new domains of experience. Throughout his experience, MB encountered situations he had not encountered previously (e.g., involvement with multiple funerals for school students and staff; courts of enquiry; police inquests; decisions about memorials). He said that as he responded to the tragedy, he understood not to assume or presume anything.

It's been a learning curve for me, and part of my journey, and I'm determined to learn from it as well. Can we gain wisdom and insight and direction and purpose in this whole matter?

MB acknowledged the essential assistance and support he gained from his team who acted to support him in the face of adversity. 


\section{Conclusion}

The Christian character of the school informed how the school responded to this tragedy. The school found its strength, guidance, and support in their belief that their God would uphold them through their grief. Prayer, faith, and support for one another were central to their response. Media coverage of the tragedy meant that the New Zealand public were aware of the tragedy, and literally thousands of people from across New Zealand, and from overseas, assisted the school through prayer, through their messages of condolence, and with offers of practical assistance. In the large number of media interviews involving the school principal, particularly in the first two or three weeks following the tragedy, the public observed Christian values and guidance at work as the principal responded openly to the many questions posed by journalists. The principal consistently demonstrated compassion for all involved in the tragedy including the staff at the outdoor centre, he provided information where possible, and he resisted attributing any blame. The conductance of the school's dealing with the tragedy was an exemplar in school crisis response, management, and Christian leadership (see below for honours awarded the principal for his leadership). Evidence of the impact of media coverage involving the principal was such that in the year following the tragedy, the school was "inundated" with enrolment applications, and extra staff had to be employed to process the large volume of applications.

In times of adversity, many people find strength to cope, and to support others. It appears from MB's report of the Year 12 students' examination results in the year following the tragedy, that almost all of the students who had lost peers in the tragedy had been able to cope and to move ahead. Following the tragedy, students had been given constant psychosocial support by their school as they worked through their extraordinary experience. MB expects that students of ECC will likely be strengthened in character and resilience through their experience of the tragedy and the considerable demands placed on them, demands far beyond those normally expected of young students.

The principal and his support team themselves have also coped with loss and grief since the disaster. From the moment the news of the tragedy broke, and for the following two years in particular, demands continued to be made, to a greater or lesser extent, on the principal's time and energy. The principal has supported students and staff in their grief, he has supported grieving families, and he has attended to the many, varied, and prolonged administrative and legal procedures related to the tragedy. In respect of his role in this tragedy, he reports that he has learnt and grown himself, and that he is determined to continue learning from this experience.

Through the tragedy in 2008 that affected the lives of so many students, staff, and families of ECC, it is the school principal's belief that he, his staff, the governance body of the school, the students, and families alike will be better prepared for other difficulties they may encounter in their lives in the future. The present study is limited to only the principal's perspective of how the Christian foundation of ECC assisted the individuals impacted by this tragedy. The scope of the present study did not include investigating coping with the tragedy from the children's perspective.

Children are poorly represented in the coping and Post-Traumatic Growth (PTG) literature, and there is a need for future studies to investigate factors that enable (and that inhibit) coping and PTG in children. Importantly, it appears there are almost no studies to date that have asked the children themselves what was helpful, what was not helpful, and what they needed in the immediate aftermath of a tragedy, and in the time that follows. Such studies are necessary to help us understand traumatic experiences from the child's perspective. Also, through longitudinal studies, it may be possible to measure the impact of Christian support following a tragedy to identify significant factors that enable faith-based coping and growth in children. Such studies could have implications for psychosocial support, as well as for suggesting therapeutic implications for assisting school children exposed to a traumatic event.

\section{Public and Peer Acknowledgement of the Principal's Leadership through the Tragedy}

In August 2008 Murray Burton received the New Zealand Principal's Federation Service with Distinction award "in recognition for his truly inspirational leadership through the Elim crisis" (Auckland Primary Principal's Association, 2008).

In 2009, the year following the tragedy, North \& South magazine, a pre-eminent New Zealand current affairs magazine, named Murray Burton as New Zealander of the year (see Wane, 2009).

In April 2011, Murray Burton was awarded The New Zealand Order of Merit (MNZM) for services to the 
community. The award recognises Mr. Burton's management of his school and the local community following the tragedy. This honour, instituted by Royal Warrant in 1996, is awarded to people who have "rendered meritorious service to the Crown and the nation or who have become distinguished by their eminence, talents, contributions, or other merits” (Department of the Prime Minister and Cabinet, 2011).

\section{Acknowledgements}

I thank Mr. Murray Burton for his cooperation with this study. There had been considerable and continuing demands on Mr. Burton regarding the tragedy in the two years between the tragedy occurring and the time I interviewed him for the present study. I am grateful for his time and his interest in this study. I am indebted to Mr. Burton for sharing his personal, professional, and Christian perspective of the event with me, thus enabling a study to be conducted that is ultimately expected to benefit other school principals who may face a tragedy in their school.

The author is grateful for funding contributions for this study, provided by the School of Psychology at Massey University, and a Massey University Research Award for a group of studies that includes the present study.

\section{References}

Auckland Primary Principals Association (2008). HPPA Conference Summary. Auckland Primary Principals Association. http://www.appa.org.nz/CustomContentRetrieve.aspx?ID=89508

Bussell, V. A., \& Naus, M. J. (2010). A Longitudinal Investigation of Coping and Posttraumatic Growth in Breast Cancer Surviviors. Journal of Psychosocial Oncology, 28, 61-78. http://dx.doi.org/10.1080/07347330903438958

Cornell, D. G., \& Sheras, P. L. (1998). Common Errors in School Crisis Response: Learning from Our Mistakes. Psychology in the Schools, 35, 297-307. http://dx.doi.org/10.1002/(SICI)1520-6807(199807)35:3<297::AID-PITS9>3.0.CO;2-K

Department of the Prime Minister and Cabinet (2011). Special Honours List-2 April 2011. http://www.dpmc.govt.nz/honours/lists/list.asp?id=51

Holy Bible (Biblica, 2011). Contemporary English Version. http://www.biblegateway.com/passage/?search

Joshi, P. T., \& Lewin, S. M. (2004). Disaster, Terrorism, and Children. Psychiatric Annals, 34, 710-717.

Koenig, H. G., McCullough, M. E., \& Larson, D. B. (2001). Handbook of Religion and Health. New York: Oxford University Press. http://dx.doi.org/10.1093/acprof:oso/9780195118667.001.0001

Laufer, A., Raz-Hamama, Y., Levine, S. Z., \& Solomon, Z. (2009). Posttraumatic Growth in Adolescence: The Role of Religiosity, Distress, and Forgiveness. Journal of Social and Clinical Psychology, 28, 862-880. http://dx.doi.org/10.1521/jscp.2009.28.7.862

McCarthy, J. F., O’Connell, D. J., \& Hall, D. T. (2005). Leading Beyond the Tragedy: The Balance of Personal Identity and Adaptability. Leadership and Organisational Development Journal, 26, 458-475. http://dx.doi.org/10.1108/01437730510617663

Meisenhelder, J. B. (2002). Terrorism, Posttraumatic Stress, and Religious Coping. Issues in Mental Health Nursing, 23, 771-782. http://dx.doi.org/10.1080/01612840260433659

Ministry of Education (2010). School Types. http://www.minedu.govt.nz/Boards/EffectiveGovernance/FlexibilityBoardStructures/SchoolingStructuresAndGovernance Options.aspx

O’Leary, V. E. (1998). Strength in the Face of Adversity: Individual and Social Thriving. Journal of Social Issues, 54, 425446. http://dx.doi.org/10.1111/j.1540-4560.1998.tb01228.x

Tix, A. P., \& Frazier, P. A. (1998). The Use of Religious Coping during Stressful Life Events: Main Effects, Moderation, and Mediation. Journal of Consulting and Clinical Psychology, 66, 411-422.

http://dx.doi.org/10.1037/0022-006X.66.2.411

Wane, J. (2009). New Zealander of the Year. Overall Winner: Murray Burton. North \& South, 37-43. 